УДК: 355.23(477):378.5

\author{
Костянтин Юрійович Сурков ${ }^{1}$ \\ Руслан Володимирович Бабенко ${ }^{2}$
}

${ }^{1}$ Відокремлений структурний підрозділ Національного авіаційного університету “Льотна академія Національного авіаційного університету”, Кропивницький, Украӥна

${ }^{2}$ Національний університет оборони Украӥни імені Івана Черняховського, Київ, Украӥна

\title{
МЕТОД ІНТЕГРАЛЬНОГО ОЦІНЮВАННЯ РЕЗУЛЬТАТІВ ПІДГОТОВКИ ДИСПЕТЧЕРІВ ПОВІТРЯНОГО РУХУ
}

\begin{abstract}
Прочеси підготовки диспетчерів управління повітряним рухом вимагають розробки системи управління якістю їх підготовки, яка повинна дозволити оцінити результати підготовки диспетчерів повітряного руху. Основним завданням оцінки рівня підготовки диспетчерів є отримання інформаџії, необхідної для обтрунтованого судження про успішність проходження ними курсу підготовки та оцінки очікуваної якості їх роботи. В статті з'ясовано, щчо при підготовці диспетчерів, помилкові дії яких впливають на виконання завдань управління повітряним рухом, поряд із прямими показниками використовуються також “непрямі показники” - показники оцінки фізіологічної “иіни” організму за досягнуті результати. Вибір непрямих показників обумовлений характером діяльності диспетчера. Як правило, непрямі показники спрямовані на очінку інтенсивності нервово-емочійної напруги диспетчера $в$ прочесі тренувань.

Відповідність умов, створюваних в інтересах контролю алгоритму роботи диспетчерів, реальним забезпечується застосуванням імітаційно-тренажної апаратури з високим значенням показників повноти $і$ якості відтворення інформачійної моделі, залученням натурних засобів для створення обстановки, щуо відповідає реальним умовам управління повітряним рухом.

В статті розроблений метод очінювання результатів підготовки диспетчерів повітряного руху, щзо трунтується на формалізації очинки за допомогою теорії нечітких множин. Розроблено апарат формалізачії правил одержання очінок індивідуальної та групової діяльності диспетчерів. В основу розробленого апарата формалізаиії покладена теорія нечітких множин. Даний підхід дозволив привести оичінки різної природи до єдиної формальної системи та урахувати їх, використовуючи єдині формальні правила.
\end{abstract}

Ключові слова: адаптивні навчальні системи, диспетчер управління повітряним рухом, нечіткі множини, лінгвістичні змінні, критерії оцінювання, підготовка.

\section{Вступ}

Зростання інтенсивності повітряного руху, розвиток авіаційної техніки, широке впровадження безпілотних авіаційних систем потребує нових підходів та формує нові вимоги до підготовки диспетчерів повітряного руху. Процеси підготовки вимагають розробки нових методів оцінювання результатів та прийняття рішення щодо готовності диспетчерів до самостійного виконання завдань.

Постановка проблеми. Для підвищення ефективності підготовки диспетчерів повітряного руху з використанням тренажерів передбачається постійний контроль дій тих, яких навчають, при вирішенні ними поставлених завдань. Це дозволяє оцінити дії операторів, коректувати програму індивідуального навчання, визначати ступінь готовності оператора до практичної роботи. На сьогоднішній день при проведенні тренажерної підготовки контроль операторської діяльності здійснюється інструктором на базі засобів пульта контролю й керування на всіх етапах тренування. Оцінка дій диспетчерів при цьому виробляється частково в процесі тренування; частково - після його завершення на основі апостеріорного аналізу зафіксованих у процесі тренування показників. Тому актуальним $є$ вдосконалювання системи контролю дій диспетчерів повітряного руху, що дозволяє інтегрально оцінювати різні показники якості.

Аналіз останніх досліджень і публікацій. Дослідження щодо адаптивного навчання операторів бойового управління (військова сфера) та диспетчерів повітряного руху (цивільна сфера) розкривається в роботах С. М. Неділько, С. П. Борсука, І. І. Верещагіна, О. В. Ізвалова, А. С. Пальоного, М. А. Павленка, О. І. Тимочко, Г. С. Степанова, В. Г. Чернова, Ю. В. Чинченко. В той же час можна зробити висновок про неповне вирішення задачі інтегрального оцінювання результатів підготовки диспетчерів повітряного pyxy.

Метою статті $є$ розкриття основних положень методу інтегрального оцінювання результатів 
підготовки диспетчерів повітряного руху.

\section{Виклад основного матеріалу} дослідження

Основним завданням оцінки рівня підготовки диспетчерів $\epsilon$ отримання інформації, необхідної для обгрунтованого судження про успішність проходження ними курсу підготовки та оцінки очікуваної якості їх роботи [1].

Об'єктивність контролю рівня підготовки диспетчерів досягається:

вибором відповідних інформативних показників;

об'єктивною реєстрацією вихідних даних, необхідних для розрахунку та оцінки обраних показників;

обгрунтуванням граничних значень показників (нормативів) для визначення оцінок;

відповідністю умов роботи на адаптивних тренажерах реальним.

Рівень підготовки оцінюють по так званих “прямих показниках" - які характеризують ступінь відповідності результатів діяльності диспетчерів поставленому завданню [2,3].

При підготовці диспетчерів, помилкові дії яких впливають на виконання завдань управління повітряним рухом, поряд із прямими показниками використовуються також “непрямі показники” показники оцінки фізіологічної “ціни” організму за досягнуті результати. Вибір непрямих показників обумовлений характером діяльності диспетчера. Як правило, непрямі показники спрямовані на оцінку інтенсивності нервовоемоційної напруги диспетчера в процесі тренувань. У даній роботі такі показники не розглядаються в силу неоднозначності їхнього впливу на діяльність диспетчера [4].

Прямі показники можуть бути частковими та узагальненими. Часткові показники призначені для оцінки якості виконання диспетчером окремих операцій, узагальнені - для оцінки рівня підготовки зміни диспетчерів у цілому.

До часткових показників оцінки рівня підготовки відносяться:

імовірність виконання операції (або всього алгоритму роботи) за час, що не перевищує заданого;

імовірність виконання операції (або всього алгоритму роботи) 3 помилками, що не перевищують заданої величини;

імовірність того, що кількість безпомилкових рішень, прийнятих у процесі роботи, не менш заданої величини;

середнє значення (математичне очікування) контрольованого показника;

середньоквадратичне відхилення (дисперсія) контрольованого показника;

сукупність середнього значення та середньоквадратичного відхилення контрольованого показника.
Узагальненим показником оцінки рівня підготовки диспетчера $\epsilon$ ймовірність виконання поставленого перед ним завдання.

Забезпечення інформативності вихідних даних досягають реалізацією наступних вимог:

дані, що отримуються в процесі контролю, повинні бути об'єктивними та забезпечувати розрахунок обраних показників із заданою вірогідністю;

контрольовані параметри повинні мати досить великий діапазон варіювання при зміні рівня підготовки.

Обгрунтованість граничних значень показників (нормативів рівнів) залежить від реалізації вимог, викладених нижче, із застосуванням відповідних методів математичної статистики.

Відповідність умов, створюваних в інтересах контролю алгоритму роботи диспетчерів, реальним забезпечується застосуванням імітаційно-тренажної апаратури 3 високим значенням показників повноти і якості відтворення інформаційної моделі, залученням натурних засобів для створення обстановки, що відповідає реальним умовам управління повітряним рухом [1$6]$.

Процес визначення імовірнісних показників виконання завдання полягає в обчисленні кількості сприятливих подій до загального числа спостережень:

$$
\mathrm{P}=\frac{\mathrm{n}}{\mathrm{N}}
$$

для яких:

$$
\mathrm{t}_{\mathrm{i}} \leq \mathrm{T}_{0}, \mathrm{r}_{\mathrm{i}} \leq \mathrm{R}_{0}, \mathrm{~L}_{\mathrm{i}} \leq \mathrm{L}_{0}
$$

При оцінці рівня підготовки можливі два типи помилок:

помилкове завищення оцінки рівня підготовки (помилка першого роду - $\alpha$ );

помилкове заниження оцінки рівня підготовки (помилка другого роду - $\beta$ ).

Вірогідність контролю оцінюють імовірністю появи помилок $\alpha$ та $\beta$. Через різну значимість помилок першого й другого роду практично завжди при контролі підготовки диспетчерів необхідно дотримувати умови $\alpha \geq \beta$. Найпоширенішими методами контролю рівня підготовки є [1]:

метод однократного контролю;

метод послідовного контролю.

У першому випадку здійснюють певну обмежену кількість контрольних вимірів результатів діяльності в оцінюваних умовах. По характеристиках цих вимірів приймається рішення щодо того, якому рівню підготовки відповідає контрольований диспетчер.

При методі послідовного контролю кількість контрольованих вимірів заздалегідь не фіксують. Послідовно здійснюють разові виміри й 
визначають необхідні характеристики, по яких приймають одне із двох рішень:

результати відповідають певному рівню підготовки;

остаточне рішення не приймається, контроль триває.

Контроль закінчується при прийнятті першого рішення. Для оцінки рівня підготовки (при будьякому методі контролю) необхідно встановити граничні значення показника. При однократному контролі враховується вид контрольованого показника - дискретний або безперервний.

Для одержання повної інтегральної оцінки враховуються всі показники якості діяльності диспетчерів. У роботі оцінюються прямі показники діяльності: час реакції, адекватність і загальний час рішення завдання по усуненню результатів помилкових дій [2].

Розглянуті показники якості діяльності диспетчерів можуть дати одну або кілька розрізнених оцінок кожного диспетчера. Іноді цього недостатньо. Необхідно дати інтегральну оцінку якості діяльності диспетчерів як сукупність всіх показників якості навчання й підготовки в ході проведення тренажерної підготовки. Така сукупність може бути визначена як ефективність діяльності диспетчера. При іiі визначенні необхідно враховувати наступне.

При визначенні важливості кожного часткового показника, тобто “ваги” кожного показника в загальній оцінці, необхідно розрізняти види роботи диспетчерів, що характеризуються своїми особливостями. Так діяльність диспетчера, а саме, час реакції на помилки, що допускаються, і на їх усунення в ході вирішення завдань управління повітряним об'єктом є пріоритетними. При визначенні інтегральної оцінки приймаємо, що зазначені вище показники мають однакову “вагу”, тому що є однаково визначальними в діяльності диспетчера.
Часткові показники вимірюються в різних величинах, що викликає наявність одночасно різнорідної інформації:

точкових вимірів і значень параметрів;

допустимих інтервалів зміни параметрів;

статистичних законів, що характеризують оцінку розподілу окремих величин;

лінгвістичних критеріїв і обмежень, отриманих від фахівців-експертів і т.д.

Отже, вони повинні бути приведені до безрозмірного та нормованого виду.

Можливим шляхом для прийняття рішень по оцінці діяльності диспетчера в цьому випадку $є$ використання теорії нечітких множин. Вона дозволяє формалізувати процес обліку різних видів невизначеності [3].

Нечітке лінгвістичне моделювання засноване на наборі лінгвістичних правил і оперує поняттям лінгвістичної змінної. Використання лінгвістичних змінних дозволяє переносити на математичну мову такі поняття як “висока”, “низька”, ступеня виразності або прояву параметрів. Значеннями лінгвістичної змінної $\epsilon$ слова, а не числа. Наприклад, інтегральна оцінка ефективності діяльності диспетчера стане лінгвістичною змінною, якщо значеннями іiі будуть не числа, а слова - лінгвістичні терми, наприклад, “незадовільна”, “задовільна”, “добра”. Нечітке правило представляється в наступному виді: якщо $\epsilon$ (нечітка передумова), тоді є (нечіткий висновок).

У процесі автоматизованого поточного та завершального контролю знань (рис. 1), використовуються завдання; їхні правила (алгоритми) відповідей (рішення); безпосередньо самі відповіді; у більшості випадків, оцінки за виконання завдань; нормативи виконання завдань i рекомендації 3 інтерпретації результатів [1,7,8].

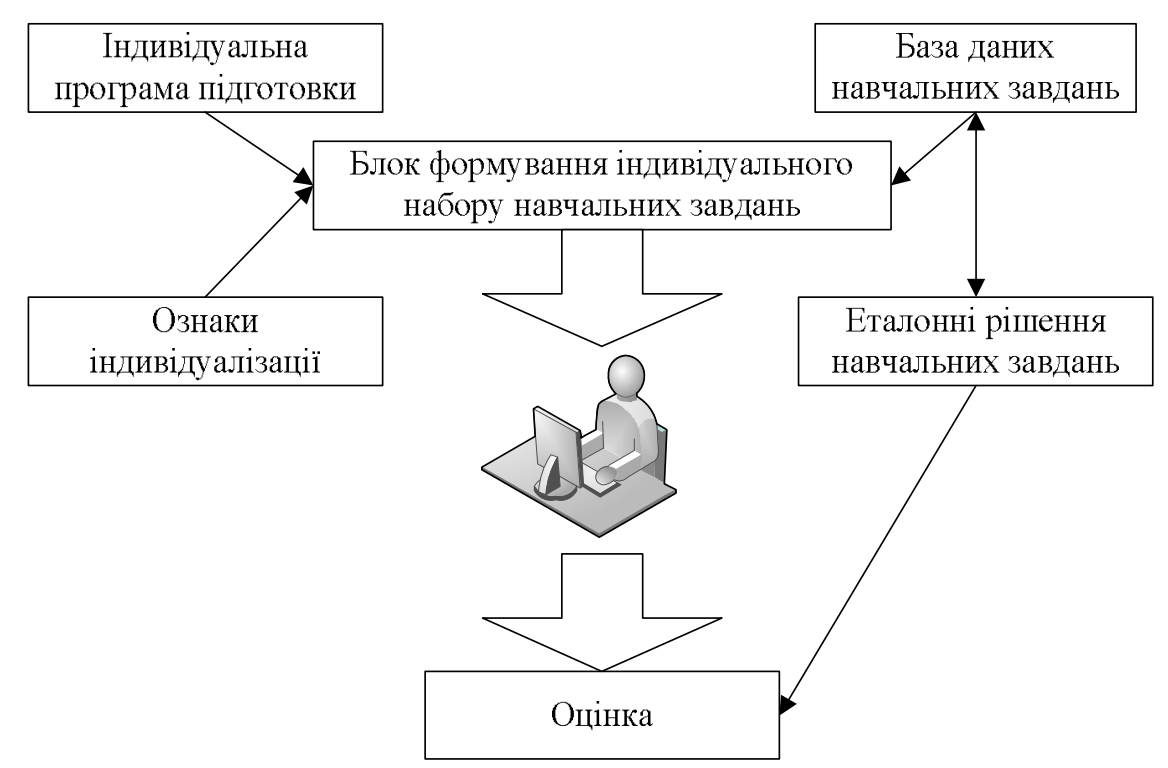

Рис.1. - Загальна структура системи автоматизованого контролю діяльності диспетчера 
Принципи оцінювання діяльності диспетчера в системі контролю:

наявність логічної схеми рішення контрольних завдань;

єдиний підхід до оцінки знань для різних видів контрольних завдань; наявність інтегруючих процедур, спрямованих на зменшення часу контролю та кількості питань.

Логічна схема завдань (ЛС3) розробляється викладачем і може бути побудована аналогічно [3]. ЛС3 має вигляд графа (рис. 2).

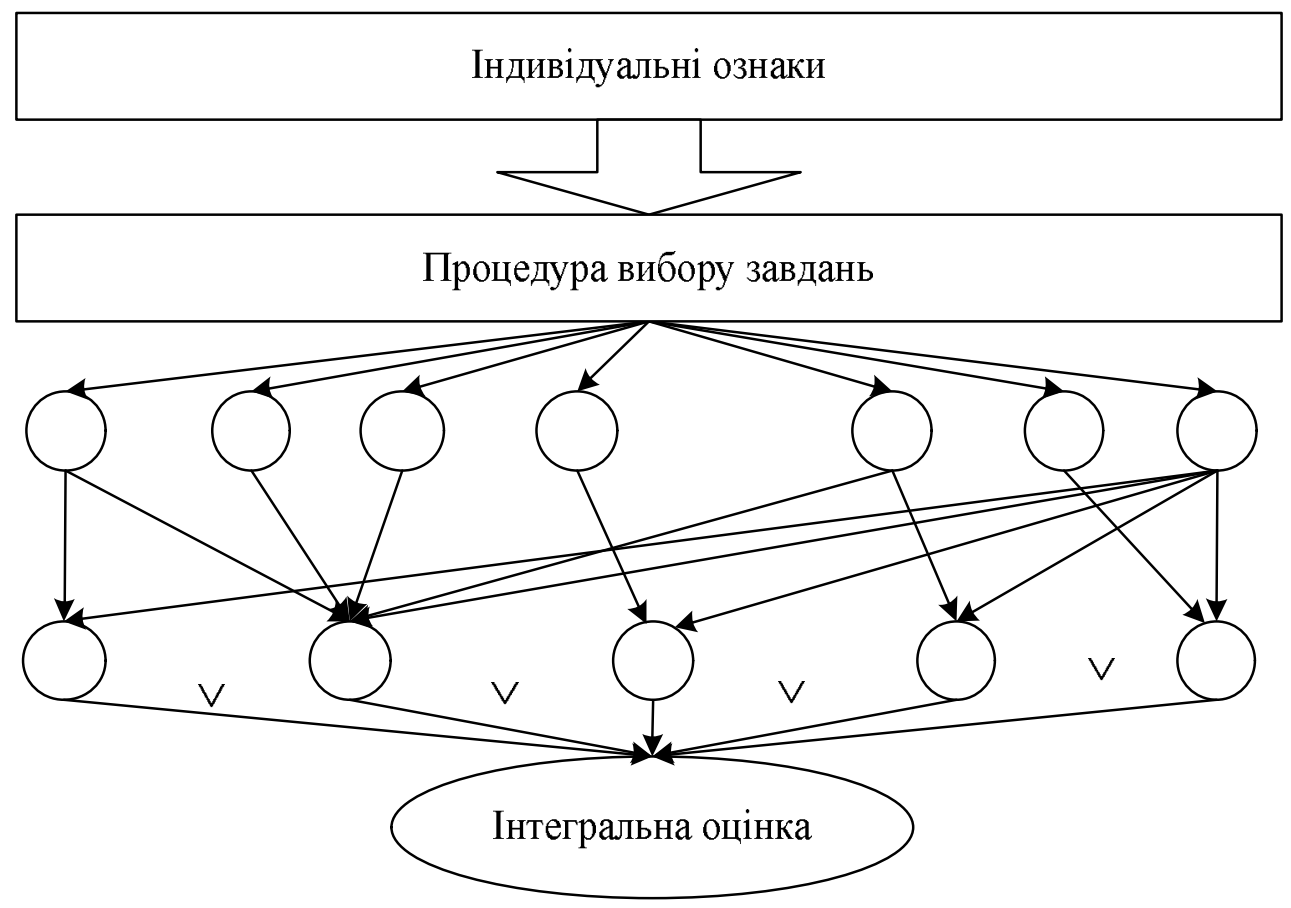

Рис.2. - Схема методу формування інтегральної оцінки в системі контролю диспетчерів повітряного руху

На нижньому рівні представлені дані, що характеризують конкретного диспетчера. Після вибору питань (завдань), визначаються такі, які мають кількісну інтерпретацію. Відповіді на них враховуються при визначенні подальшої структури питань. При контролі питання нижнього рівня вибираються відповідно до програми навчання за принципом від простого до складного. У графа $\epsilon$ вершини, які мають якісне подання результатів рішення. Вони у вигляді предикатної функції визначають перехід до групи питань іншого завдання при наборі певної кількості балів. $€$ вершини, що мають логічне подання результату, яке формується внаслідок виконання певних кон'юнктивних або диз'юнктивних умов. Вони передбачають перехід до більше простих завдань у випадку неправильного їх рішення або закінчення тестування (тренування) у випадку відмінних знань (успішного виконання плану навчання). Правильне формування структури ЛС3 і iï інформаційне насичення є першим фактором, що визначає ефективне функціонування системи контролю знань диспетчерів управління повітряним рухом.

\section{Висновки і перспективи подальших досліджень}

Таким чином, в статті розкриті основні положення методу інтегрального оцінювання підготовки диспетчерів повітряного руху, що грунтується на формалізації оцінки за допомогою теорії нечітких множин. Розроблено апарат формалізації правил одержання оцінок індивідуальної та групової діяльності диспетчерів.

Подальшим напрямком досліджень є розробка методики отримання персональної оцінки диспетчера повітряного руху в ході його підготовки.

\section{Jimepamypa}

1. Павленко М.А. Принципы построения перспективных тренажерных систем подготовки операторов АСУ динамическими объектами / М.А. Павленко, А.И. Тимочко, Г.С. Степанов,
В.Г. Чернов // Сучасні інформаційні технології у сфері безпеки та оборони. - 2014. - № 1. - С. 112-117. 2. Извалов А. В. Разработка алгоритмов автоматической генерации упражнения на 
диспетчерском тренажере для развития требуемых навыков / А. В. Извалов, В. Н. Неделько, С. Н. Неделько. // Наукові праці академії. - Вип. XII. Кіровоград, 2007. - С. 274-282. 3. Пальоний А. С. Розробка методу i моделей оцінки діяльності авіадиспетчерів / А. С. Пальоний // Системи управління, навігації та зв'язку. - 2015. - Вип. 3. - С. 120-127. 4. Chernov V. G. Problems of the education and training of combat control officers / V.G. Chernov, A. I. Tymochko, M. A. Pavlenko, О. Y. Dorosh // Радіоелектронні i комп’ютерні системи. - Х., 2014. - № 2 (66). - С. 121124. 5. Чернов В. Г. Проблеми підготовки офіцерів бойового управління авіацією / В.Г. Чернов, А. И. Тимочко, М. А. Павленко, О. Р. Мартинюк // Сучасні інформаційні технології у сфері безпеки та оборони. 2014. - № 2 (20). - С. 125-129. 6. Артюшин Л. М. Методика оцінювання технічної досконалості авіаційних тренажерних комплексів / Л. М. Артюшин, В. І. Мірненко, О. Є. Мавренков // Збірник наукових праць Державного науково-дослідного інституту авіації. - К., 2016. - Вип. 12. - С. 27-34. 7. Чернов В. Г. Метод формирования набора индивидуальных тестовых заданий для оценки уровня подготовки оператора АСУ в процессе тренажной подготовки / В. Г. Чернов, М. А. Павленко, А. И. Тимочко, Д. Ю. Свистунов, Н. А. Королюк // Системи управління, навігації та зв'язку. - К., 2014. - Вип. 2 (30). - С. 63-68. 8. Неделько С. Н. Разработка системы критериев оценки для автоматизированного анали за действий авиадиспетчеров на тренажерах обслуживания воздушного движения [Текст] / С. Н. Неделько, В. А. Григорецкий, А. С. Паленный // Наукові праці академії. - вип. IX / за ред. Р. М. Макарова Кіровоград: ДЛАУ, 2005. - С. 387-400.

\title{
МЕТОД ИНТЕГРАЛЬНОГО ОЦЕНИВАНИЯ РЕЗУЛЬТАТОВ ПОДГОТОВКИ ДИСПЕТЧЕРОВ ВОЗДУШНОГО ДВИЖЕНИЯ
}

\author{
Константин Юрьевич Сурков ${ }^{1}$ \\ Руслан Владимирович Бабенко ${ }^{2}$
}

\author{
${ }^{1}$ Обособленное структурное подразделение Национального авиационного университета “Летная \\ академия Национального авиационного университета”, Кропивницкий, Украина \\ ${ }^{2}$ Национальный университет обороны Украины имени Ивана Черняховского, Киев, Украина
}

Процессы подготовки диспетчеров управления воздушным движением требуют разработки системь управления качеством их подготовки, которое должно позволять оценить результать подготовки диспетчеров воздушного движения. Основным заданием оценки уровня подготовки диспетчеров есть получение информации, необходимой для обоснованного суждения об успешном прохождении ими курса подготовки и оценки ожидаемого качества их работы. В статье выяснено, что при подготовке диспетчеров, ошибочные действия которых влияют на выполнение заданий управления воздушным движением, наряду с прямыми показателями используются также "непрямые показатели” - показатели оценки физиологической “иены” организма за достигнутые результаты. Выбор непрямых показателей обусловлен характером деятельности диспетчера. Как правило, непрямые показатели направлены на оценку интенсивности нервно-эмоционального напряжения диспетчера в процессе тренировок.

Соответствие условий, создаваемых в интересах контроля алгоритма роботы диспетчеров, реальным обеспечивается применением имитационно-тренажерной аппаратуры с высоким значением показателей полноты и качества воспроизведения информационной модели, привлечением натурных средств для создания обстановки, которая соответствует реальным условиям управления воздушным движением.

В статье разработан метод оценивания результатов подготовки диспетчеров воздушного движения, который базируется на формализации оченки с помощьью теории нечетких множеств. Разработан аппарат формализации правил получения оченок индивидуальной и групповой деятельности диспетчеров. В основу разработанного аппарата формализации положена теория нечетких множеств. Данный подход дал возможность привести оценки разной природы к единой формальной системе и учесть их, используя единье формальные правила.

Ключевые слова: адаптивные системы обучения, диспетчер управления воздушным движением, нечеткие множества, лингвистические переменные, критерии оценивания, подготовка.

\section{INTEGRAL ASSESSMENT METHOD RESULTS OF PREPARATION AIR TRAFFIC CONTROLLER}

\author{
Kostiantyn Surkov ${ }^{1}$ \\ Ruslan Babenko ${ }^{2}$
}
${ }^{1}$ Separated Structural Subdivision of the National Aviation University "Flight Academy of the National Aviation University", Kropyvnytskyi, Ukraine
${ }^{2}$ National Defence University of Ukraine named after Ivan Cherniakhovsky, Kyiv, Ukraine


The processes of training air traffic controllers require the development of a quality management system for their training, which should allow to evaluate the results of their training. The main task of assessing the quality of training is to obtain the information necessary for proper conclusion on the success of their training course and assess the expected quality of their work. The article establishes that when training controllers, whose erroneous actions influence the performance of air traffic control tasks, "indirect indicators" are also used along with direct indicators - indicators of the body's physiological "price" for the results achieved. The choice of indirect indicators is due to the nature of the activity of the controllers. As a rule, indirect indicators are aimed at assessing the intensity of the neuro-emotional stress of the air traffic controller in the process of training.

Compliance with the conditions created in the interest of controlling the controller's algorithm of operation is provided by using simulation equipment with a high value of the indicators of completeness and quality of reproduction of the information model, using natural resources to create an environment corresponding to the actual conditions of air traffic control.

The article developed a method for evaluating the results of training air traffic controllers, based on the formalization of assessment using the theory of fuzzy sets. An apparatus has been developed to formalize the rules for obtaining estimates of individual and group activities of dispatchers. This approach allowed us to bring estimates of different nature into a single formal system and take them into account using common formal rules.

Keywords: adaptive learning systems, air traffic control controller, fuzzy sets, linguistic variables, evaluation criteria, training.

\section{References}

1. M. A. Pavlenko, A.I. Tymochko, G.S. Stepanov, V. G. Chernov (2014), Principles of construction of ACS operator training perspective simulator systems by dynamic objects. [Principi pobudovi perspektivnih trenagernih system pidgotovki operatoriv ASU dinamichnimi objektami], Suchasni informacijni tekhnologhiji u sferi bezpeky ta oborony, No. 1, pp. 112-117. 2. A. V. Izvalov, V. N. Nedelko, S. N. Nedelko (2007), Development of algorithms for automatic generation of exercises on the air traffic controller simulator for the development of the required skills. [Razrabotka algoritmov avtomaticheskoj generacii upragnenija na dispetcherskom trenagere dlia razvitija trebuemih navikov], Naukovi praci akademii, No. 12, pp. 274-282. 3. A. S. Palennyi (2015), Development of assessment method and models of air traffic controller performance. [Rozrobka metodu i modelei ocinki dijalnosti aviadispetcheriv], Sistemi upravlinnia, navigacii ta zviazku, No. 3, pp. 120-127. 4. V. G. Chernov, A. I. Tymochko, M. A. Pavlenko, O. Y. Dorosh (2014), Problems of the education and training of combat control officers, Radioelektronni i komputerni sistemi, No. 2 (66), pp. 121124. 5. V. G. Chernov, A. I. Tymochko, M. A. Pavlenko, O. R. Martyniuk (2014), Problems of training aviation command and control officers. [Problemi pidgotovki oficeriv bojovogo upravlinnia aviacieu], Suchasni informacijni tekhnologhiji u sferi bezpeky ta oborony, No. 2 (20), pp. 125-129. 6. L. M. Artushin, V.I. Mirnenko, O. E. Mavrenkov (2016), Technique for assessing the technical perfection of aviation simulator complexes. [Metodika ocinuvannia tehnichnoi doskonalosti aviaciinih trenagernih kompleksiv], Zbirnik naukovih prac Dergavnogo naukovodoslidnogo institute aviacii, No. 12, pp. 27-34. 7. V. G. Chernov, M. A. Pavlenko, A. I. Tymochko, D. U. Svistunov, N. A. Koroluk (2014), Method of forming set individual test tasks for assessment level of operator training ACS during simulator training. [Metod formirovanija nabora individualnih testovih zadanij dlia ocenki urovnia podgotovki operatora ASU v processe trenagnoi podgotovki], Sistemi upravlinnia, navigacii ta zviazku, No. 2 (30), pp. 63-68. 8. S. N. Nedelko, V. A. Grigoreckyi, A. S. Palennyi (2005), Development of a system of evaluation criteria for the automated analysis of the actions of air traffic controllers on simulators of air traffic services. [Razrabotka sistemi kriteriev ocenki dlia avtomatizirovannogo analiza deistviy aviadispetcherov na trenagerah obslugivaniya vozdushnogo dvigeniya], Naukovi praci akademii, No. 9, pp. 387-400. 